\title{
Determinants of Rural Poverty in Southern Ethiopia: Empirical Evidence from Gedeo Zone
}

\author{
Berhanu Getinet Kibret(Asst. Professor) \\ Department Of Economics, Hawassa University; Ethiopia
}

\begin{abstract}
Poverty especially in the rural areas has turned out to be a great global social and economic challenge in this $21^{\text {st }}$ century. Poverty is a complex, interlocked and multidimensional phenomenon. It is lack and deprivations of decent life sustaining resources that people experiences at various degrees so as different life chances. This study was carried out in southern Ethiopia with empirical evidence from Gedeo zone. The specific objective of the study was to investigate determinants of rural poverty. In order to achieve its objective, the study made use of the primary data collected through survey and interview using semi structured questionnaire. The study employed a multistage sampling procedure for sample selection. Employing cross sectional design, the research was undertaken on a random sample of 325 households in the study area. An absolute poverty line set in the study area using CBN approach; based on food basket of $2200 \mathrm{Kcal}$ per adult per day was used to identify the poor from non-poor households. Accordingly, the absolute poverty line of Birr 4463.35 was used in the study area. The binary logistic regression model was employed so as to investigate determinants of rural poverty in the study area. The model output revealed that the number of livestock holding, land size, number of chicken owned, beehives ownership, Annual Income per Adult Equivalent, use of modern agricultural inputs, involvement in non-farm activities and saving habit of households were variables found with negative impact and significant determinants of poverty. Whereas, the variables with positive impact on household poverty and found to be significant were family size, age of household head and dependency ratio. Therefore, alleviation of rural poverty in the study area in particular and rural Ethiopia in general requires policy formulation and adoption of strategies with respect to those variables found to have a significant effect on poverty status of rural households.
\end{abstract}

Keywords: Rural, poverty; Logistic regression; Determinants

DOI: $10.7176 / \mathrm{JESD} / 11-7-06$

Publication date: April $30^{\text {th }} 2020$

\section{Introduction}

Poverty is a multi-dimensional phenomenon and its manifestations are deep, pervasive and intractable any where in developing world. It has been indicated in ( Todaro,1997) that it is a condition in which the underprivileged part of the society do not have and lack access to adequate food, shelter, education and health services, are exposed to violence, and live in state of unemployment, vulnerability and powerlessness. It has a variety of indicators such as levels of income, consumption, social and of vulnerability to risks and socio-political access and participation. The most common approach to the measurement of poverty is based on incomes or consumption levels(Berhanu,2019). It is widely understood that an individual is considered poor if consumption falls below some minimum level necessary to meet basic needs (usually a $2200 \mathrm{kcl} /$ day) which is a poverty line (World Bank,2004).Poverty is predominantly a rural phenomenon in the majority of developing world. Contemporary studies indicate that poverty rates are typically higher in rural areas; about $2 / 3$ of the absolutely poor in this part of the world live in rural areas. Also, human development indicators and service provision tend to be worse in the rural sections in these countries (Ravallion, 2016). In fact, due to the Sustainable Development Goals (SDGs) are now calling for the elimination of extreme poverty for all people everywhere by 2030. Thus, development efforts, social mobilization, investment and renewed attention from States will need to focus on rural areas (IPC-IG, 2019).

Agriculture is the primary livelihood source and the sector remains the most important for poor people in rural areas, and their productive capacity could potentially be key to expanding future food production in more sustainable and nutritious ways; though, rural populations are also increasingly diversifying their livelihoods( FAO,2019). The majority of the Ethiopian population is living in rural areas and agriculture is the main stay of the economy and at present, about $72.7 \%$ of the country's population engages in agricultural activities and generates income for household consumption. Beside, the country generates the lion share of its foreign currency earnings from the export of agricultural goods and the sector contributes $34.9 \%$ to the country's GDP(NBE,2017). Despite this, the sector remains vulnerable to external shocks; notably droughts and adverse terms of trade. Moreover, the number of poor people in rural areas of Ethiopia exceeds the capacity of agriculture to provide sustainable livelihood opportunities. The low productivity and subsistence nature of the sector, farmers have been compelled to practice over cultivation, overgrazing, and expansion of cultivable land at the expense of the forest, pasture and sloppy areas, which eventually causes degradation of the natural resource base and declined productivity thus exacerbating poverty. The study by IPC-IG(2019) also reported that in Ethiopia much of the rural population still tries to survive in low-technology, low-productivity small-scale farming or livestock rearing 
which are not sufficient to absorb the growing rural youth in the country. As the result, quite a significant proportion of population lives in poverty.

Indeed, there are widely varying reasons for the deep rooted poverty in Ethiopia. FSS (2002) argues that the causes of abject rural poverty include lack of income, pervasive diseases and malnutrition and lack of decent health care, schooling and potable water, which are compounded by high rural unemployment, fast depletion of natural resources and the increasing shrinkage of cultivable land. According to Tassew(2004), lack of asset and endowment such as land, oxen and off-farm income opportunities at micro level further exacerbate chronic poverty and food insecurity.

According to World Bank (2018a), the overall global poverty has fallen over the last decades, including in rural areas though still it continues to be persistent in rural areas and communities; and about 80 per cent of the world's most severe poor people live in rural areas. In many regions of the world, rural areas have experienced few positive changes in their overall wellbeing and still it is also in rural areas where poverty is most severe. Indeed, the progress of poverty alleviation strategies in Ethiopia since last decade is promising and has improved macro economic performance of the country. However, as reported by NPC (2017), it had a limited impact on the poverty at micro level so that there are no large-scale improvements in the living conditions of rural community.

\section{Statement of the Problem}

Poverty in the rural areas in the 21 st century brings new challenges and also opportunities for governments and organizations across the world calling for coordination for pro-poor development. The contemporary reports on poverty indicate that almost about 80 per cent of the world's extremely poor people live in rural areas. Poverty continues to be persistent in lives of rural community; and is both more prevalent and acute in the rural than the urban counterpart (IPC-IG,2019). Besides, a large household surveys conducted in 89 developing countries by UNICEF reveals that the global poor are predominantly rural(about 80\%), young(44 percent are 14 years old or younger), poorly educated(with 39 percent have no formal education at all), mostly employed in the agricultural sector(64\%), and live in larger households with more children(UNICEF, 2016). This will surely be changed, especially if governments and development organizations are serious about achieving the Sustainable Development Goals.

Poverty is manifested in low per capita income, low literacy rate, low primary school enrollment ratio, limited access to health services, safe water and sanitation facilities, high rate of infant, child and maternal mortality as well as short life expectancy. Despite the fact that the Ethiopian economy extensively depends on agriculture, low productivity (due to unreliable rainfall, high population growth and structural bottlenecks), production and market linkages are the daunting challenges for the sector that obviously results in poverty of the rural households. To end this, Ethiopia has started the fight against poverty and demonstrated a strong commitment to poverty reduction by adopting poverty reduction and economic transformation strategies (MOFED, 2012). This has been witnessed by the robust and sustained growth of the country in the last two decades. The per capita income has continuously increased over the period and reached 883 USD in 2017 (NBE, 2017) though it is far lower than the average per capita income for the Sub-Saharan Africa(SSA) which was 1661 USD in the same year(World Bank,2017).

The poverty studies conducted in Ethiopia have indicated that poverty among the poor remains a challenge and it has been part of lives of the rural community in the country. In this regard, it was reported that the proportion of food poor and absolutely poor people respectively are $33.6 \%$ and $23.5 \%$ in rural areas (NPC, 2016). This vividly indicates that rural areas harbor the bulk of the poor and there is still a grave of rural mass poverty in the country and poverty is unambiguously a rural phenomenon. Hence, the urgency of researching rural poverty is beyond doubt and no wonder then that poverty reduction is high on the agenda of the government. Thus, investigation of the root causes of poverty and designing a strategy are imperative.

The empirics on rural poverty indicate that poverty correlates and determinants are context specific and multidimensional in characteristics. A study by Ayalneh et al.(2005) in three districts of Ethiopia : Alemaya, Hitosa and Merhabete by using binary logistic model reported that rural poverty in Ethiopia has strong relationship with failures of entitlements such as lack of resource endowments to rural life sustaining assets such as land, human capital, income and oxen. Muhdin(2015) conducted a research in Dodola woreda, Oromia Regional State and investigated the determinants of rural poverty using binary logistic and concluded that family size has positively related to poverty where as number of income sources of the household, livestock and farm land ownership are related to household poverty status negatively. Besides, Nega (2015) undertook study in Gulomekeda Woreda of Tigray region employing the same model and found that family size and dependency ratio have positive relation with poverty of households. However, farm size, total livestock owned, value of asset, educational status of the household head, income, access to credit and access to off-farm income have strong negative association with poverty status of households. A national level study in Ethiopia by Teshome and Sharma(2014) employed a logistic regression model to identify determinants of wellbeing of the household by considering per capita consumption as a dependent variable. The study reported that the variables dependency ratio, family size, gender of household head, and marital status have odd ratios greater than one, which means that these variables are 
positively correlated with the probability of being poor. On the contrary, the variables like agricultural landholding, family size, age of household head, education level of household head, being self-employment and employment in formal sector of the household head all have odd ratios lower than one, that implies these variables have negative correlation with the probability of being poor. Recently, Ermiyas et al.(2019) also conducted a study to identify determinants of rural poverty in Dejen district Amhara region using probit model and found that household size, sex of households, dependency ratio and livestock ownership are found to be the key determinants of rural poverty among which total number of livestock a household owned and sex of household heads are negatively correlated with poverty status ; family size and dependency ratio are positively related to poverty status of households. Furthermore, Ahmed (2013) conducted study on determinants of rural poverty in southern and northern Ethiopia and it used dynamic probit model. It found that the likelihood of falling into poverty increases due to previous experience in poverty and drought; but the socioeconomic variables like land size, oxen and other tropical livestock units, cash crop production and ownership of durable assets have significant role in reducing the probability of falling into poverty and demographic variables like household size, age of the household head and being headed by female are less important as correlates of poverty and statistically insignificant.

The studies so far conducted on the rural poverty; much if not all of these, concentrate on and reflect the national picture and other different local realities and failed to consider the poverty situations and correlates in rural areas of the country in depth at the grass root levels. In this regard, Dercon and Krishnan (1998) strongly advise that one should be careful about the implications derived from poverty study results at national level, because it hides many important differences that exist in different locations; and hence are not likely to be reliable for particular localities. Also, these previous studies results may not show the current reality due to that poverty is dynamic and heterogeneous by its nature which reminds us that there is no single policy panacea and effective efforts to reduce rural poverty should depend on dynamics in different contexts. Indeed, it is crucial to understand local variations of poverty causes for appropriate rural poverty reduction prescriptions. The study of rural poverty is remaining in question because the arguments for and against the approaches has been many and the results they provide have not been consistent to each other and thus no consensus has been reached. Moreover, poverty determining factors of rural households has not been yet studied in the rural areas of Gedeo zone of southern Ethiopia. This paper has the paramount importance in bridging such knowledge gaps and thereby adds a brick to the poverty reduction endeavor, which is a hot issue for Ethiopia. Thus, this study aims to investigate the determinants of poverty in southern Ethiopia.

\section{Significance of the Study}

Rural poverty alleviation intervention needs a thorough understanding of the determinants of poverty. Besides adding to the body of knowledge on the subject, the output of the study could also be informative for government, donors and non-governmental organizations appropriate intervention in the study area. The study helps the rural households that the can design ways to escape poverty. Besides, the study helps policy makers formulate appropriate interventions and for assessing progress of alleviation policies and strategies of the country. The study also would be a literature for further studies on related issues.

\section{Methodology of the Study \\ 4.1 Research Design}

A Research design is a logical framework to undertake a given study; and the selection and applicability a specific design rests primarily on the specific question a researcher seeks to investigate(Berger et al, 2009). In line with this, cross sectional survey design was employed in this study with both with quantitative and qualitative approaches. Survey methods are extremely efficient in terms of providing large amounts of data at relatively low cost in a short period of time, and has come to be virtually synonymous with social scientific methodology (Smith, 1975). This design enables a researcher to collect data on more than one case at a snapshot(in a given point in time). Besides, it is less time consuming and cheaper than others.

\subsection{Sampling Techniques and Sample Size}

The method of sampling technique applied in this study was multi-stage sampling and households were the sampling units. At the first stage, two districts: Wonago and Kochere were selected purposively from Gedeo zone, southern Ethiopia. This is due to that they are densely populated districts and where a number of NGOs do provide aid for the community, implying that poverty prevails in the study area(Gedeo Zone Finance And Development Bureau,2015). This reality is witnessed by the pilot survey conducted by the researcher. In the second stage, six kebles were selected using simple random sampling (3 kebeles from each two districts). In third stage, a probability proportional to sample size (PPS) sampling procedure was employed to determine sample households from each woreda and each kebele. In line with this, 334 sample households were selected. A sample size of 186 from Wonago and 138 from Kochere districts were selected. Finally, respondent households were identified using systematic random sampling from the list of the rural households. 
The sample size $\mathrm{n}$ for the study was determined using the following formula (Cochran, 1977) as:

$$
n=\frac{\frac{Z^{2} \alpha / 2 P(1-P)}{d^{2}}}{1+\frac{1}{N}\left(\frac{Z^{2} \alpha / 2 P(1-P)}{d^{2}}-1\right)}
$$

Where; $\mathrm{d}$ is the absolute precision, and $Z_{\alpha / 2}$ is value of standard normal deviate at level of significance, $\alpha$. The values taken are $\mathrm{P}=0.5,(1-\mathrm{P})=0.5, \mathrm{~d}=0.03$, and $Z_{\alpha / 2}=1.96$ with $\alpha=0.05 ; \mathrm{N}$ is the total population of 64,920 which is the sum of the total respective 30,599 and 34,321 rural households in Wonago and Kochere districts. For this study, a sample size $\mathrm{n}=334$ was determined. The sample size of households for the randomly selected kebeles for the study were determined proportionally using probability proportional to sample size (PPS) technique. The three kebeles included in the study from Wonago district were Sugale, Tokicha and Mekonisa; where as Baya, Haniku and Biloya were the other three kebeles selected from Kochore district.

\subsection{Data types, sources and collection tools}

The data for was collected from both primary and secondary sources. For the primary data, sample households were interviewed by using semi-structured survey questionnaire. This is, because administration of questionnaire through interviewing respondents is a source of primary data which enables to ascertain both subjective and objective facts (Mayntz, 1976). That is, for persons of varying levels of literacy, personal face-to-face interview is the most satisfactory and common approach. In addition, the primary data was collected through focus group discussions, interview of key informants and personal observations. The focus groups from each study woredas were selected from elder men, women and the youth in kebeles that were selected for purpose in the study area. Interview was also conducted with knowledgeable local informants, who among others include zone and woreda Agriculture and Rural development officials. White (2002) indicates that using quantitative and qualitative approaches together yields synergy in research. The secondary data was also collected from secondary sources such as reports for triangulation purposes.

\subsection{Model Specification and Estimation Setting poverty line}

For investigating the determinants of poverty, the first step taken was distinguishing the poor and non poor is poverty line which quantifies the various indicators of well being as the yardstick starting point for poverty analysis. When income or consumption is used as indicator, households are considered as poor when either their income or consumption is below poverty line and non-poor otherwise (Rath, 1996). Of course, consumption based measures are preferred since they provide more adequate picture of well being than income. Theories of economics suggest that per capita expenditure is the best indicator of welfare, but it considers that households assumed to be optimizing consumers maximizing continuous utility functions defined over commodities(Glewwe, 1987 cited in Teshome and Sharma,2014).

The poverty line was constructed using the Cost of Basic Needs (CBN) approach and in this approach, the predetermined normative nutritional minimum requirement of 2,200 Kcal per adult per day of World Bank standard was used(World Bank,2004). Establishing a line starts with defining and selecting a basket of food items typically consumed by the rural poor based on the food consumption behavior and expenditure pattern of the rural community in the study. The quantity of the basket is determined in such a way that the given bundle meets the predetermined level of minimum energy intake per day of $2200 \mathrm{kcal} / \mathrm{day}$. This is consistent to FSS (2002) and MOFED(2012) that they followed the same procedure to set poverty line in Ethiopia.

The cost of the food bundle was calculated using local market prices in order to reflect the actual food poverty line in the locality of the study area. Then after, a specific allowance for the non-food component consistent with the spending patterns of the poor is added to the food poverty line to reach at absolute poverty line. Allowance was given to the non-food expenditure component to estimate the absolute poverty line by dividing the food poverty line by the average food share for households. That is, allowance was made in such way that the food poverty line is divided by the food share of the poorest 25 per cent of the population to arrive at the absolute poverty line

The value of minimum amount of consumed food items at an average price of the identified food items in the local markets plus the sum of estimated minimum amount of money needed to cover the non-food expenses per Adult Equivalent $(\mathrm{AE})^{1}$ per annum were used as a threshold beyond which the household is said to be poor or non-

${ }^{1}$ The Conversion factor used to estimate Adult Equivalent was adopted from Ravallion and Bidani (1994) and uses OECD scale as: AE $=1+$ $0.7(\mathrm{~N}$ adults -1$)+0.5 \mathrm{Nchildren}$. 
poor.

After setting poverty line, the actual consumption expenditure of a rural household was calculated and used to identify the poor from non-poor households in reference to the absolute poverty line. The actual household expenditure is considered as that of total annual expenditure incurred by the household on consumption (including own produce). It includes the sum of own produce consumed (cereal crops, cash crops, coffee, fruits ,honey , poultry products, meat and other livestock products), expenses on purchased food items (cereals, sugar, salt, tealeaf $\&$ others), clothing, health care, education, social obligation (religious contributions, wedding, funeral ceremonies, etc), household utensils, fuel, transportation and other miscellaneous expenditures of the households. The actual expenditure/per adult/annum is calculated by summing up all the expenditure components and dividing by total adult equivalent (AE) of the household.

\section{The probability of being poor}

Once the poor and non poor groups of households have been identified, the next procedure was to pinpoint characteristics that are correlated with poverty. In order to investigate the determinants of poverty, the binary logistic regression model was employed. Given the dependent variable of main interest that a household may be classified as poor or non-poor, a binary logistic model can be used for the analysis of the data. The dependent variable is a dichotomous dummy, which takes a value of one or zero when a household is poor or non-poor respectively. That is, the probability that an individual with a given set of household attributes falls in one category rather than the other( poor or non-poor) would be determined. In this model, we directly estimate the probability of an event occurring. An event occurrence is the probability of being poor while no event occurrence refers not being poor. Consider that a household is poor $(Y=1)$ if per capita household food consumption is less than 2200 $\mathrm{kcal}$ per day or non poor $(\mathrm{Y}=0)$ if the food consumption shortfall is less than or equal to zero. A set of factors (independent variables), mentioned elsewhere, gathered in a vector $\mathrm{X}$, could explain the response so that;

$$
\mathrm{Yi}=\beta \mathrm{iXi}+\mathrm{Ui}---------------(1)
$$

Where; $\mathrm{Yi}$ is the underlying latent variable that indexes the measure of poverty(Dependent variable, Ui is stochastic error term, and $\beta$ is a column vector of parameter to be estimated.

According to Greene (1993), the cumulative distribution of ui is logistic and thus a logit model has been employed for this poverty study and the probability of being poor for the household is given by:

$\operatorname{Prob}(\mathrm{Y}=1)=\frac{\mathrm{e}^{\beta 0+\beta 1 \mathrm{Xi}}}{1+\mathrm{e}^{\beta 0+\beta \mathrm{Xi}}}$

Where, $\beta o$ and $\beta 1$ are coefficients to be estimated from data, $\mathrm{X}$ is explanatory variable (that includes age of household head, family size, dependency ratio, annual household income, education level of household head, size of land the household owned, household livestock ownership, number of chicken owned, number of beehives owned, use of modern agricultural inputs, access to nearest market centre, involvement in non-farm activities, access to credit, house hold saving habit); e is the base of the natural logarithms. For more than one independent variable the model can be written as:

$\operatorname{Prob}(\mathrm{Y}=1)=\frac{\mathrm{e}^{\mathrm{Z}}}{1+\mathrm{e}^{\mathrm{Z}}}$

Where, $\mathrm{Z}$ is the linear combination of independent variables written as:

$Z=\beta o+\beta 1 X 1+\beta 2 X 2+\ldots+\beta n X n$

If we let $\mathrm{Xi}_{\mathrm{k}}$ be the $\mathrm{K}^{\text {th }}$ element of the vector independent variable $\mathrm{Xi}$, and $\beta \mathrm{k}$ be the $\mathrm{K}^{\text {th }}$ element of $\beta$, then the marginal effect of a particular independent variable, $\mathrm{Xi}$, on the probability of the occurrence of the response is given by (Maddala, 1993):

$$
\frac{\partial \mathrm{P}(\mathrm{Y}=1)}{\partial \mathrm{Xi}}=\frac{\mathrm{e}^{\beta 0+\beta 1 \mathrm{Xi}}}{\left[1+\mathrm{e}^{\beta 0+\beta 1 \mathrm{Xi}}\right]^{2}} * \beta \mathrm{k}
$$

The probability of an event not occurring is estimated as: Prob $(\mathrm{Y}=0)=1-\operatorname{Prob}(\mathrm{Y}=1)$. We can further rearrange the equation so as it is easy to understand and interpret the coefficients of the variables in the model. For this purpose, model can be re-written in terms of the log odds of being poor which is a logit. The 'odds' of an event happening are defined as the probability of the event occurring divided by the probability of it not occurring. That is, here in this study the odds ratio is the probability of being poor divided by the probability of not being poor. The effects of independent variables on the probability of being poor is the change of odds ratio as the independent variables change.

Logistic regression models the logarithm of the odds of an outcome as a linear combination of explanatory variables.

$\log \left[\frac{\operatorname{Prob}(\mathrm{Y}=1)}{\operatorname{Prob}(\mathrm{Y}=0)}=\beta \mathrm{o}+\beta 1 \mathrm{X} 1+\beta 2 \mathrm{X} 2+\ldots+\beta \mathrm{nXn}\right.$

Since it is easier to think of odds rather than log odds, the above equation can be re-written in terms of odds as: $\frac{\operatorname{Prob}(\mathrm{Y}=1 ; \text { poverty })}{\operatorname{Prob}(\mathrm{Y}=0 \cdot \text { no poverty })}=\mathrm{e}^{\beta 0+\beta 1 \mathrm{X} 1+\cdots+\beta \mathrm{iXi}=\mathrm{e}^{\beta 0} \mathrm{e}^{\beta 1 \mathrm{X} 1} \ldots . . . \mathrm{e}^{\beta \mathrm{iXi}}}$

In this odds equation, $\beta \mathrm{i}$ is the factor by which the odds change when the $\mathrm{i}^{\text {th }}$ explanatory variable changes. If 
$\beta \mathrm{i}$ is positive, the factor will be greater than 1 , which implies that the odds are increased. And, if $\beta \mathrm{i}$ is negative, the factor will be less than 1 , which again shows the fact that the odds are decreased and the increase or existence of explanatory variable reduces the probability of being poor. Furthermore, when $\beta \mathrm{i}$ is zero the factor equals 1 , which leaves the odds unchanged and this implies that there is no impact of the respective variable on poverty status(Norusis, 1994).

The logitistic regression model was employed due to that it yields unbiased estimates even if there is nonlinearity involved in using the cumulative normal distribution for estimating poverty. Besides, it imposes constant parameters over the entire distribution and thus assumes that the impact of any household characteristics on welfare is constant over the whole sample. The logit model directly gives us a probabilistic explanation about poverty and thus are increasingly used for the analysis of correlates of poverty (Alemayehu et al., 2001). Logistic regression is preferred to other models, such as linear models in the analysis of dichotomous outcomes variable due to its simpler meaningful interpretability as the logarithm of the odds ratio(Hosmer and Lemeshew,2000). Thus, this study employed binary logistic regression model.

Before estimating the logit model, the Multicollinearity problem was checked for continuous explanatory variables using a Variance Inflation Factor (VIF); and a VIF value greater than 10 , is used as a signal for existence of severe Multicollinearity. Similarly, the interaction between discrete variables, coefficients of contingency were computed. Indeed, the contingency coefficient has a value between 0 and 1 where 0 indicates no multicollinearity and 1 indicates a high degree of Multicollinearity. Additionally, hetroscedasticity problem was checked with Breusch-Pagan test(Gujarati,2004).

\section{Description of Variables \& Working Hypothesis}

Once the analytical procedure and its requirements are determined, it is necessary to identify the potential explanatory variables and describe their measurements. The major explanatory variables that are expected to have influence on the household to be poor or not poor in the study area are presented and explained in table-1 below. Table-1: Summary of variable descriptions, types, measurements and expected signs of variables

\begin{tabular}{|c|c|c|}
\hline $\begin{array}{lll}\begin{array}{l}\text { Variables } \\
\text { description }\end{array} & \text { Code and } \\
\end{array}$ & Type and measurement of variables & $\begin{array}{l}\text { Expected } \\
\text { sign }\end{array}$ \\
\hline \multicolumn{3}{|l|}{ Dependent variable } \\
\hline $\begin{array}{l}\text { POVSTAT(Poverty status of } \\
\text { a household) }\end{array}$ & $\begin{array}{l}\text { A dichotomous variable with } 1 \text { for a household who is poor } \\
\text { whereas it takes the value } 0 \text { for a non-poor household. }\end{array}$ & \\
\hline \multicolumn{3}{|l|}{ Independent variables } \\
\hline $\begin{array}{l}\text { HHAGEH(Age of Household } \\
\text { Head) }\end{array}$ & $\begin{array}{l}\text { A Continuous variable designating age of the house hold head. As } \\
\text { the age of the household head increases, the person is expected to } \\
\text { acquire more experience and endowed with more assets so as less } \\
\text { likely to experience poverty. }\end{array}$ & - \\
\hline $\begin{array}{l}\text { HFAMSZAE } \\
\text { (Household Family Size) }\end{array}$ & $\begin{array}{l}\text { This is a Continuous variable which represents the total number of } \\
\text { adult equivalent that live together under the same household. }\end{array}$ & + \\
\hline $\begin{array}{l}\text { DEPENDCR(Dependency } \\
\text { Ratio) }\end{array}$ & $\begin{array}{l}\text { A Continuous variable that represents the ratio of children under } \\
\text { age } 15 \text { and old age of above } 64 \text { to working age population aged } \\
\text { between 15-64 expressed in terms of adult equivalent. }\end{array}$ & + \\
\hline $\begin{array}{l}\text { EDUCHHH(Education level } \\
\text { of Household head) }\end{array}$ & $\begin{array}{l}\text { It represents dummy for primary educational attainment of the } \\
\text { household head: } 1 \text { if the head has completed primary education } \\
\text { and } 0 \text { if not. }\end{array}$ & - \\
\hline $\begin{array}{l}\text { SOHLO(Size Of Land The } \\
\text { Household Owned) }\end{array}$ & $\begin{array}{l}\text { This represents size of cultivated land the household owned and is } \\
\text { continuous variable. }\end{array}$ & - \\
\hline $\begin{array}{l}\text { TLUAE(Household } \\
\text { Livestock Ownership) }\end{array}$ & $\begin{array}{l}\text { This variable is continuous \&represents Total Livestock Unit of } \\
\text { animals measured in Tropical Livestock Units (TLU) }\end{array}$ & - \\
\hline $\begin{array}{l}\text { NOCH(Number Of Chicken } \\
\text { Owned) }\end{array}$ & $\begin{array}{l}\text { It is a continuous variable that represents number of chicken } \\
\text { owned by a household }\end{array}$ & - \\
\hline $\begin{array}{l}\text { NOBO(Number Of Beehives } \\
\text { Owned) }\end{array}$ & $\begin{array}{l}\text { It is a continuous variable and represents number of traditional } \\
\text { and/or modern beehives owned by the household }\end{array}$ & - \\
\hline $\begin{array}{l}\text { MAGINPU (Use Of modern } \\
\text { Agricultural Inputs) }\end{array}$ & $\begin{array}{l}\text { This is a dummy variable for use of agricultural inputs : } 1 \text { if the } \\
\text { household use inputs and } 0 \text { otherwise }\end{array}$ & - \\
\hline $\begin{array}{l}\text { ATNMC } \\
\text { (Access to Nearest Market } \\
\text { Centre) }\end{array}$ & $\begin{array}{l}\text { Dummy for household's distance from market centre: } 1 \text { if the } \\
\text { household nearest to market centre and } 0 \text { otherwise. }\end{array}$ & - \\
\hline
\end{tabular}




\begin{tabular}{|l|l|c|}
\hline $\begin{array}{l}\text { Variables Code and } \\
\text { description }\end{array}$ & \multicolumn{1}{|c|}{ Type and measurement of variables } & $\begin{array}{l}\text { Expected } \\
\text { sign }\end{array}$ \\
\hline $\begin{array}{l}\text { HINFAC } \\
\text { (Involvement In Non-Farm } \\
\text { Activities) }\end{array}$ & $\begin{array}{l}\text { It is a dummy variable for household's involvement in non-farm } \\
\text { activities: } 1 \text { if the household is involved in non-farm activities and } \\
\text { 0 otherwise. }\end{array}$ & - \\
\hline $\begin{array}{l}\text { ACCRED } \\
\text { (Access To Credit) }\end{array}$ & $\begin{array}{l}\text { This is a dummy variable for access to credit: 1 if the household } \\
\text { has access to credit and 0 otherwise. }\end{array}$ & - \\
\hline $\begin{array}{l}\text { HHSHB(House Hold Saving } \\
\text { Habit) }\end{array}$ & $\begin{array}{l}\text { A dummy for household's saving habit: 1 if the household has the } \\
\text { habit of saving and 0 otherwise. }\end{array}$ & - \\
\hline $\begin{array}{l}\text { AINCPAE(Annual Income } \\
\text { per adult equivalent) }\end{array}$ & $\begin{array}{l}\text { It is a variable which is continuous and represents annual income } \\
\text { per adult equivalent earned by a household in a year per adult } \\
\text { equivalent }\end{array}$ & - \\
\hline
\end{tabular}

Source: Own coding, definition and measurement, 2017

\section{RESULTS AND DISCUSSION}

\section{Poverty Lines}

To investigate the determinants of poverty, first poverty line should be calculated for the study area on the basis of predetermined cost of obtaining the $2200 \mathrm{kcal}$ per adult per day minimum calorie requirement for subsistence and this is consistent with (Ravallion and Bidani, 1994). The calorie share of the diets to the minimum calorie required for subsistence was calculated to arrive at the level of calorie and quantities of food group items that gives the $2200 \mathrm{kcal}$. The quantities of the food item groups are valued using average local market prices in order to reflect the actual food poverty line in the locality. Dividing the food poverty line by the average food share of the lowest consumption quartile gives an absolute poverty line.

In this study, the poverty line estimated by Berhanu (2019) in the study area during the same study period was used to identify the poor from non-poor households. The food poverty line calculated was found to be ETB Birr 3952.74. Then this food poverty line is divided by the food share of the poorest 25 per cent of the population to arrive at the absolute poverty line. The food share of the lowest income quartile of 88.56 percent was used to estimate an allowance of non-food expenditure; indeed that was found to be ETB 510.61. Therefore, the sum of food and non-food expenditures gives absolute poverty line of Birr 4463.35. The average household size was 4.82 adult equivalent units in the zone, needs an income of Birr 926.006 per adult equivalent per annum to escape absolute poverty.

\section{Determinants of rural poverty}

To investigate the determinants of rural household poverty in the study area, a logit model was employed to estimate the effects of the hypothesized explanatory variables on the probabilities of being non poor or not. Before the estimation of the model parameters, the model was checked for problem of Multicollinearity. To this end, the variance inflation factor (VIF) was used to test the degree of Multicollinearity among the continuous variables and there is no such problem. For discrete variables, contingency coefficient was employed and it was confirmed that there is no Multicollinearity problem. Moreover, to test the hetroscedasticity problem, Breusch-Pagan test was employed in this study following (Williams, 2012); and there was no such problem and error terms are homoscedastic.

The goodness-of-fit measures determine the accuracy of the model prediction approximates to the observed data. The Pearson Model Chi-Square test was used for assessing the overall significance of logistic model at $1 \%$ level of significance. That is, the test indicates that the hypothesis that all coefficients except the intercept are equal to zero is rejected and at least one of the predictors' regression coefficients is not equal to zero. As it is indicated in table-2, Pearson model Chi-Square test of 41.48 is significant at less than $1 \%$ probability level.

In the model, the variable POVSTAT (Household Poverty Status) was used as a dichotomous dependent variable, with value of 1 indicating the probability of being poor and, 0 otherwise. A total of 8 continuous and 6 discrete explanatory variables were included in the model for analysis. Among the explanatory variables considered in the logistic regression model, 11 variables were found to be the determining factors of the state of poverty with up to $10 \%$ of probability level. Among the explanatory variables fitted into the model age of household head, household family size, dependency ratio, size of land the household owned, livestock ownership, number of chicken owned, beehives ownership, use of modern agricultural inputs, involvement in non-farm activities, saving habit and annual income per adult equivalent were found to be significant in determining household poverty status; whereas, the rest 3 explanatory variables in the model such as access to credit and educational level of household head and access to nearest market centre (see table-2) were found to be insignificant on poverty status of the rural households in the study area.

To analyze the effects of independent variables on the probability of being poor, the change of odds ratio as the independent variables change would be considered. As it is clearly indicated in table-2 of the regression result 
that the variables age of household head (HHAGEH), household family size (HFAMSZAE), dependency ratio(DEPENDCR) have odd ratios greater than one, which means that these variables are positively correlated with the probability of being poor of rural households; but the other remaining 11 variables SOHLO, TLUAE, NOCH, NOBO, MAGINPU,ATNMC, HINFAC,ACCRED, HHSHB, and AINCPAE in the model have odd ratios lower than one with the implication that variables have negatively related with the probability of being poor in the study area. Here, it indicates that HHAGEH, HFAMSZAE and DEPENDCR have respective contributions of $18.4 \%, 20.5 \% 54 \%$ in increasing the likelihood of being poor. When we consider, the negatively correlated variables with probability to be a poor household, it indicates that a household is less likely to be poorer with respect to the variable. For instance, household with livestock ownership (TLUAE) is $84.5 \%$ less likely to be poor than those households with no livestock ownership.

The model reveals that age of household head (HHAGEH) is found to be very significant at $5 \%$ probability level and has positive association with the household poverty. It has positive sign of effect opposite to the expected, negative sign. That is, the households with older age tend to be poor than younger household heads. This shows that as the household heads are getting older the probability that he/she falls into poverty is likely or the probability of the household to be poor increases as the age of the household head increases. This might be an argument that as the age of the household heads increases there is a probability of having large number of children which contribute to large family size. This finding is inconsistent with Teshome and Sharma(2014) but inline. The odds ratio of 1.184 for age of household head implies that, keeping the other variables constant, the odds ratio in favor of being poor increases by a factor of 1.184 as age increases by one year. The possible explanation for such positive association is that an older household heads have larger number of children that increases the dependency ratio in the family. Besides, the reason why the younger household heads are less probable to be poor might be explained by their capacity to involve in nonfarm activities that would increase the income of the households and increases the probability of the households to escape poverty.

Household family size(HFAMSZAE) appeared to be significant in determining poverty status of rural households in the study area. This variable is significant at $10 \%$ probability level and has positive relation with the household poverty. This positive relationship of the variable with the household poverty status indicates that the odds ratio in favor of the probability of being poor increases with an increase in the family size. It is consistent to Muhdin(2015), Nega (2015) and Ermiyas et al.(2019). The odds ratio of 1.205 for family size implies that, other things being constant, the probability of being poor increases by a factor of 1.205 as family size increases by one adult equivalent. This is in agreement with the hypothesis that the family size is likely to play a role in determining the state of poverty at household level. This clearly shows the importance of family planning to control population growth in the study area.

Table-2: Logistic regression results for the determinants of rural poverty (POVSTAT $=1$ )

\begin{tabular}{|l|l|l|c|c|c|}
\hline Variables & Coefficients & S.E & Wald Statistics & Sig. Level & Odds Ratio \\
\hline CONSTANT & -0.118 & 0.1120 & 1.110 & 0.000 & 0.885 \\
HHAGEH & 0.163 & 0.0515 & 10.020 & $0.001^{*}$ & 1.184 \\
HFAMSZAE & 0.186 & 0.1055 & 3.106 & $0.078^{* * *}$ & 1.205 \\
DEPENDCR & 0.432 & 0.0838 & 26.592 & $.000^{*}$ & 1.540 \\
EDUCHHH & -0.137 & 4.3323 & 0.001 & 0.995 & 0.087 \\
SOHLO & -3.210 & 0.3301 & 94.568 & $0.000^{*}$ & 0.040 \\
TLUAE & -0.168 & 0.0436 & 60.079 & $0.000^{*}$ & 0.845 \\
NOCH & -0.137 & 0.0222 & 38.197 & $0.000^{*}$ & 0.872 \\
NOBO & -0.527 & 0.0865 & 37.105 & $0.000^{*}$ & 0.590 \\
MAGINPU & -1.426 & 0.5813 & 6.017 & $0.001^{*}$ & 0.228 \\
ATNMC & -0.116 & 0.1101 & 1.110 & 0.292 & 0.079 \\
HINFAC & -0.350 & 2.9580 & 0.014 & $0.012^{* *}$ & 0.437 \\
ACCRED & -1.420 & 1.7777 & 0.638 & 0.438 & 0.219 \\
HHSHB & -0.238 & 1.7266 & 0.019 & $0.023^{* *}$ & 0.098 \\
AINCPAE & -0.001 & 1.0276 & 9.469 & $0.040^{* *}$ & 0.999 \\
\hline-2 LOg Likelin & \multicolumn{4}{|c|}{}
\end{tabular}

\section{-2 Log Likelihood $=123.896$}

Pearson Chi-Square $=41.48$

Prob $>$ chi2 $=0.000$

Pseudo $\mathrm{R}^{2}=0.749$

Number of obs $=325$

$*, * *$ and $* * *$ are significant at less than $1 \%, 5 \%$ and $10 \%$ probability level respectively

Source: Own Survey output, 2017

The other variable in the model that determines the rural poverty status is the dependency ratio (DEPENDCR).

The model indicates the important role of active labor force in contributing to reduce rural poverty of households. As expected, the coefficient for the variable was found to be positive and significant at $1 \%$ level. In other words, 
the probability that a household will be poor increases as the household size increases due to an increase in the number of dependents. The odds ratio of 1.540 implies that, ceteris paribus, the probability of falling in poor group increases by a factor of 1.540 as dependent adult equivalent increases by one. One possible explanation can be those households with many dependent family members could be poor because of high dependency burden as household resources would be shared between both active and inactive family members of the household. This finding is in line with study by Nega (2015), Ermiyas et al.(2019) and Teshome and Sharma(2014).

The variable household livestock ownership (TLUAE) which is owning the livestock such as cattle, sheep and goats, are amongst the dominant means of saving and the sale of which or their products would be a source of income during economic hardship. The expectation is that those sample households with large number of these animals have better opportunity of smoothing their income overtime and hence of escaping out poverty. Besides, this enables them to purchase the required amount of food and non food consumption items even when there is a shortage of resources. As expected, the coefficient for the variable was found to be negative and significant at 1 percent. The odds ratio for total livestock holding indicates that, other things being constant, when the households' livestock holding increases by 1 TLU the probability of the household being poor decreases by a factor of 0.845 . That is, the probability of being poor increases by a factor of 0.845 as the total livestock holding decreases by 1 TLU. The finding suggests that total livestock holding is among important factors in explaining the poverty status of the sample households in the study area. It is consistent to Muhdin(2015) and Ermiyas et al.(2019).

As the households in the study area live in rural area and agriculture is the dominant means of livelihood, land is an important asset to escape poverty. This indicates that households with small or no any land size produce less for household consumption and for sale and have more chance to be poor than those having relatively large size of land. As expected in the hypothesis, the coefficient for size of the variable household land holding(SOHLO) was found to be negative at 1 percent level of significance; and it is supported by Ayalneh et al.(2005), Ahmed (2013) and Nega (2015).The odds ratio for this variable is 0.040. This indicates that maintaining other determinants constant, additional hectare of cultivated land will improve poverty status of the household by factor of 0.040 and vice versa.

The other variables in the regression model are number of chicken owned $(\mathrm{NOCH})$ and number of beehives owned (NOBO) by the sample households. The coefficient for number of chickens owned was negative and significant at 1 percent level of significance, and hence helps to escape poverty. The model output reveals that the odds ratio for the variable is 0.872 that implies that the probability of being poor increases by a factor of 0.872 as the number of chicken ownership decreases by a unit. This shows the fact that poultry production has been very critical in addressing rural poverty in the study area. Given that beekeeping is one of the sources of livelihood in the study area, the coefficient for number of beehives owned was found to be significant at 1 percent, and hence does have implication on poverty status of rural households. The odds ratio for the variable is 0.590 that indicates that the probability of being poor increases by a factor of 0.590 as the number of beehives ownership decreases by a unit. The finding witnesses that the promoting bee and honey production are important for alleviation of rural poverty.

Annual Income per adult equivalent(AINCPAE) is also the other variable fitted in the regression model and it was found to be negative and significant at $5 \%$ probability level influencing the probability of being poor of the rural households in the study area. The source of the income in study area are crops, livestock and livestock products and by-products, honey production, poultry and non- farm activities are the major sources of income and has a negative impact on the households' poverty status. The larger annual income per AE, the less the probability of being poor because higher income provides households a continuous cash flow to finance food and non-food items expenditures. This is supported by Ayalneh et al.(2005) and Nega (2015). The model output shows that the odds ratio for this variable is 0.999 which implies that, given other factors are held constant, the probability of being poor decreases by a factor of 0.999 as a household generates one more unit of on-farm income.

The modern agricultural inputs (MAGINPU) is the other variable which was found to have a negative and significant impact on poverty status of households at significance level of $1 \%$. The households that use modern agricultural inputs at a recommended rate are expected to do obtain high crop yield, and hence, have wider opportunity to escape poverty. The odds ratio for this variable was found to be 0.228 which indicates that the use of modern agricultural input favors the decrease in household poverty by 0.228 factor.

Besides, the variable involvement in non-farm activities (HINFAC) which includes petty trading, paid labor service and others was the other determinant of rural poverty. Non-farm activities apart from diversifying and providing income are important source of employment during slack period (off season) for rural communities. As expected the involvement in such activities was negatively associated with the household's poverty status and significant at $5 \%$ level. The odds ratio of 0.437 for participation in non-farm activities implies that, other things kept constant, the odds ratio in favor of being poor decreases by a factor of 0.437 . That is, the probabilities of the household to be non-poor increases by factor of 0.437 as the household participates and earns non-farm income so that are endowed with additional income and less likely to be poor. This finding is consistent with Nega (2015).

The households that have the habit of saving could invest and even use their saving at times of economic 
hardship, and hence, have better chance of escaping poverty. In this study, the saving habit was found out to have coefficients with expected negative sign and has significant impact on the household poverty status. The result of study here supports such argument that households with saving habit were found to be less vulnerable to poverty. In this regard, the odds ratio in favor of being in poverty decreases by factor of 0.098 for households having a saving culture.

\section{Conclusion and Recommendations}

\section{Conclusion}

Cost of basic needs (CBN) approach based estimated poverty line was considered to identify the poor and nonpoor households. The food poverty line calculated was found to be ETB Birr 3952.74 and this food poverty line is divided by the food share of the poorest 25 per cent of the population to arrive at the absolute poverty line. The food share of the lowest income quartile of 88.56 percent was used to estimate an allowance of non-food expenditure; indeed that was found to be ETB 510.61. Therefore, the sum of food and non-food expenditures yields the absolute poverty line of Birr 4463.35.

Moreover, logistic regression model was employed so as to identify determinants of rural poverty in the study area. The model output reveals that the number of livestock holding (TLUAE), Size Of Land The Household Owned(SOHLO),number of chicken owned(NOCH),number of beehives ownership(NOBO), Annual Income per Adult Equivalent(AINCPAE), use of modern agricultural inputs (MAGINPU), involvement in non-farm activities (HINFAC) and saving habit of households are variables found with negative impact and to be significant and determinants of poverty. Whereas, the variables with positive impact on household poverty and found to be significant were household family size (HFAMSZAE), age of household head (HHAGEH) and dependency ratio(DEPENDCR). All these variables were found to be the determinants of rural poverty in the study area. In general, the results of this study do produce the development policy implication that attaining alleviation of rural poverty in the study area in particular and rural Ethiopia in general requires adoption of multidimensional strategies and policies that address those variables found to have a significant negative and positive effect on poverty status of rural households.

\section{Recommendations}

The study result provides a meaningful insight about the correlates of rural poverty and crucial policy implications for poverty alleviation measures that enable households to escape poverty in the study area.

- Government and other donor organizations who work on rural development should synchronize their policies, strategies and efforts on overall rural livelihood improvements have to be implemented to improve the production and productivity of agriculture especially through intensification, diversify their livelihoods to non-farm activities. Indeed, when the livelihoods improve, the community can escape poverty. In this regard, especially promoting rural livelihood diversification into non-farm activities should be worked on as an option by woreda agriculture office, rural cooperatives, micro finance institutions to help escape poverty in the study area.

- The significant role of livestock calls for governments at all levels(local, regional and federal) and nongovernmental organizations should focus on productivity of livestock sector through improving livestock breeds, veterinary services, marketing, access to credit and overall management of livestock production that aimed at alleviating poverty of the poor households. Besides, the roles of beehives and chicken ownerships in improving poverty situation suggests to design development strategy for livestock sector, honey production and poultry production through application of modern technologies for improving productivity and production.

- As family size and dependency ratio increase there is no means of accessing more land to cultivation to meet the demand of large family size which aggravate the problem to access food for survival leave alone other social services such as education, health and other demands of non-food assets and resources that households will live on and secures livelihoods in the future. Thus, affirmative action based awareness creation on the impacts of population growth at the family and community level should be strongly advocated by government and NGOs.

- The strong negative association of the use of modern agricultural inputs considers promoting timely supply of modern inputs such as chemical fertilizer and improved seed coupled with appropriate credit and extension services to boost the productivity and production of the agricultural sector that in turn would improve the income level of the poor. This aspect should be strongly worked by woreda agriculture and rural development offices, rural cooperatives, micro finance institutions to help escape poverty in the study area.

- Saving habit of households in the study area was a variable found to have contribution in escaping out poverty. The households with the saving habit can invest, use their saving at times of economic hardship and even smooth their income and expenditure over time, and hence, have better chance of escaping 
poverty Therefore, awareness creation on significant role of saving habit through education, training and community teaching by financial institutions like banks, credit cooperatives and micro finance institutions has a paramount importance in addressing rural poverty.

\section{REFERENCES}

Ahmed Mohammed (2013). Determinants of Poverty in Rural Ethiopia: A Household Level Analysis. Lund university, LUP student papers: http://lup.lub.lu.se/student-papers/record/3878740.

Alemayehu Geda, Niek de Jong, Germano Mwabu and Mwangi Kimenyi (2001). Determinants of Poverty in Kenya: Household-Level Analysis. Kenya Institute for Public Policy Research and Analysis (KIPPRA). KIPPRA Discussion Paper No. 9.

Ayalneh B, Konard H, Benedikt K (2005) Determinants of Poverty in Rural Ethiopia, Quarterly J Int Agriculture 44: 101-120.

Ayalneh B, Konard H, Benedikt K (2005).Determinants of Poverty in Rural Ethiopia, Quarterly J Int Agriculture 44: 101-120.

Berger, M.P. and Wong, W.K., (2009) An Introduction to Optimal Designs for Social and Biomedical Research. Willey, Chichester. https://doi.org/10.1002/9780470746912.

Berhanu Getinet(2019). Measuring rural poverty among rural households in Gedeo Zone, SNNP Region,Ethiopia.Journal of Development and Agricultural Economics: http://www.academicjournals.org/JDAE, DOI: 10.5897/JDAE2019.1134.

Cochran, W. G.(1977) . Sampling techniques (3rd ed.). New York: John Wiley \& Sons.

Dercon S, Krishnan P (1998). Changes in poverty in rural Ethiopia 1989-1995: Measurement, Robustness tests and Decomposition, Centre for the Study of African Economies, Institute of Economics and Statistics, University of Oxford.

Ermiyas AM, Batu MM, Teka E (2019) Determinants of Rural Poverty in Ethiopia: A Household Level Analysis in the Case of Dejen Woreda. Arts Social Sci J 10: 436. doi: 10.4172/2151-6200.1000436.

FAO(2019). Reduce Rural Poverty. Food and Agriculture Organization of the United Nations website. http://www.fao.org/reduce-ruralpoverty/pathways-out-of-poverty/en. Accessed 18 February 2019.

FSS(2002). Poverty and Poverty Policy in Ethiopia. Proceedings of the workshop organized by Forum for Social Studies; Special Issue of Consultation Papers on Poverty. No. 7, Addis Ababa: March 8, 2002.

Greene, W.H. (1993). Econometric Analysis (2nd edition). Engelwood Cliffs, NJ, Prentice Hall

Gujarati(2004). Basic Econometrics, fourth edition, the McGraw-Hill Companies,2004.

Hosmer, D. and Lemeshow, S. (2000). Applied Logistic Regression, 2nd Edition, John Wiley \& Sons Inc., New York.

IPC-IG(International Policy Centre for Inclusive Growth) (2019). Poverty reduction in the 21st century

Maddala, G.S. (1993): Limited Dependent and Qualitative Variables in Econometrics. Cambridge University Press.

Mayntz R., Holm K. and Huebner R. (1976). Introduction to Empirical Sociology. Penguin Books Canada Ltd. Ontario.

MoFED( 2012). Ethiopia's Progress Towards Eradicating Poverty: An Interim Report on Poverty Analysis Study . Development Planning and Research Directorate. Ministry of Finance and Economic Development, Addis Ababa.

Muhdin M (2015). Determinants of Rural Income Poverty in Ethiopia: Case Study of Villages in Dodola District, Oromiya region, Global Journal of Management and Business Research: BEconomics and Commerce.

NBE (National Bank of Ethiopia) (2017). Annual Report 2017. Addis Ababa, Ethiopia

Nega A (2015). Determinants of Poverty in Rural Tigray, Ethiopia: Evidence from Rural Households of Gulomekeda Wereda. J Poverty Investment Development 10.

Noursis, J. Marija (1994). SPSS Advanced Statistics 6.1. SPSS Inc, U.S.A. allion, Martin. 2000. "On the Urbanization of Poverty." World Bank. Washington,D.C.

NPC( 2016). Ethiopia's Progress Towards Eradicating Poverty: An Interim Report on Poverty Analysis Study . National plan commission, FDRE, Addis Ababa.

NPC(National Plan commission). (2017). The 2017 Voluntary National Reviews on SDGs of Ethiopia: Government Commitments, National Ownership and PerformanceTrends.

Rath, N. (1996). Indian Journal of Agricultural Economics: Poverty in India Revisited. Indian Society of Agricultural Economics, Mumbai.

Ravallion(2016) The Economics of Poverty: History, Measurement, and Policy, Oxford University Press.

Ravallion, M. and Bidani, B (1994). How Robust is a Poverty Profile? World Bank Economic Review. Volume 8, No. 1.

Smith, H.W. (1975). Strategies of Social Research: The Methodological Imagination. Prentice-Hall, Inc, U.S.A.

Tassew Woldehanna (2004). New Pro-Poor Policies, Pre PRSP Experiences and the 2003-04 .Budget in Relation to Agriculture and Food Security in Ethiopia. 
Teshome Kebede and M. K. Sharma(2014). Determinant of Poverty in Ethiopia. Ethiopian Journal of Economics Vol. XXIII No 1, April 2014

Todaro, M.P. (1997). Economic Development, 6th edition, Third impression. New York.

UNICEF (2016). The State of the World's Children 2016: A Fair Chance for Every Child, New York.

White,H(2002). Combining Quantitative and Qualitative Approaches in Poverty Analysis. World Development 30 (3).

Williams(2012). Hetroscedasticity. University of Notre Dame.

World Bank (2004). Rural Development Indicators Handbook. WBI, 2004.

World Bank(2017). Global Economic Prospects: Regional Overview, Sub -Saharan,2017

World Bank(2018a). Poverty and Equity Database: The World Bank [online]. Washington, DC. http://povertydata.worldbank.org/poverty. 